\title{
Role of Neurokinin B in the Control of Female Puberty and Its Modulation by Metabolic Status
}

\author{
Víctor M. Navarro, ${ }^{1,2,3,5 *}$ Francisco Ruiz-Pino, ${ }^{1,2,3 \star}$ Miguel A. Sánchez-Garrido, ${ }^{1,2,3}$ David García-Galiano, ${ }^{1,2,3}$ \\ Samuel J. Hobbs, ${ }^{5}$ María Manfredi-Lozano, ${ }^{1,2,3}$ Silvia León, ${ }^{1,2,3}$ Susana Sangiao-Alvarellos, ${ }^{1,4}$ Juan M. Castellano, ${ }^{1,2,3}$ \\ Donald K. Clifton, ${ }^{6}$ Leonor Pinilla, ${ }^{1,2,3}$ Robert A. Steiner, ${ }^{5,6}$ and Manuel Tena-Sempere ${ }^{1,2,3}$ \\ ${ }^{1}$ Department of Cell Biology, Physiology, and Immunology, University of Córdoba, ${ }^{2}$ CIBER Fisiopatología de la Obesidad y Nutrición, and ${ }^{3}$ Instituto \\ Maimonides de Investigaciones Biomédicas de Córdoba, 14004 Córdoba, Spain, ${ }^{4}$ Department of Medicine, School of Health Science, University of A Coruña, \\ 15006 A Coruña, Spain, and Departments of ${ }^{5}$ Physiology and Biophysics, and ${ }^{6}$ Obstetrics and Gynecology, University of Washington, Seattle, Washington \\ 98185
}

Human genetic studies have revealed that neurokinin $\mathrm{B}(\mathrm{NKB})$ and its receptor, neurokinin-3 receptor (NK3R), are essential elements for normal reproduction; however, the precise role of NKB-NK3R signaling in the initiation of puberty remains unknown. We investigated here the regulation of Tac2 and Tacr3 mRNAs (encoding NKB and NK3R, respectively) in female rats and demonstrated that their hypothalamic expression is increased along postnatal maturation. At puberty, both genes were widely expressed throughout the brain, including the lateral hypothalamic area and the arcuate nucleus (ARC)/medial basal hypothalamus, where the expression of Tacr3 increased across pubertal transition. We showed that central administration of senktide (NK3R agonist) induced luteinizing hormone (LH) secretion in prepubertal and peripubertal females. Conversely, chronic infusion of an NK3R antagonist during puberty moderately delayed the timing of vaginal opening (VO) and tended to decrease LH levels. The expression of NKB and its receptor was sensitive to changes in metabolic status during puberty, as reflected by a reduction in Tacr3 (and, to a lesser extent, Tac2) expression in the ARC after a $48 \mathrm{~h}$ fast. Yet, acute LH responses to senktide in pubertal females were preserved, if not augmented, under fasting conditions, suggesting sensitization of the NKB-NK3R-gonadotropin-releasing hormone signaling pathway under metabolic distress. Moreover, repeated administration of senktide to female rats with pubertal arrest due to chronic undernutrition rescued $\mathrm{VO}$ (in $\sim 50 \%$ of animals) and potently elicited LH release. Altogether, our observations suggest that NKB-NK3R signaling plays a role in pubertal maturation and that its alterations may contribute to pubertal disorders linked to metabolic stress and negative energy balance.

\section{Introduction}

Neurokinin B (NKB), a member of the tachykinin-peptide family, has emerged as an important modulator of reproductive function. Recent studies demonstrated hypogonadotropic hypogonadism in patients bearing inactivating mutations in TAC3 or TACR3 genes, encoding NKB and its receptor [neurokinin-3 receptor (NK3R)], respectively (Topaloglu et al., 2009). Subsequent animal studies have documented potent stimulatory effects

\footnotetext{
Received Aug. 20, 2011; revised Dec. 9, 2011; accepted Dec. 21, 2011.

Author contributions: V.M.N., D.K.C., R.A.S., and M.T.-S. designed research; V.M.N., F.R.-P., M.A.S.-G., D.G.-G., S.J.H., M.M.-L., S.L., S.S.-A., J.M.C., and L.P. performed research; V.M.N., D.K.C., R.A.S., and M.T.-S. analyzed data; V.M.N., D.K.C., R.A.S., and M.T.-S. wrote the paper.

This research was supported by NIH Grant R01 HD 049651 and the Eunice Kennedy Shriver NICHD/NIH through cooperative agreement U54 HD 12629; the Marie Curie Outgoing International Fellowship within the 7th Framework Programme of the European Union; Mary Gates Endowment for undergraduate students (to S.J.H.; University of Washington); and Ministerio de Ciencia e Innovación, Spain, Research Grants BFU 2008-00984 and BFU 2011-25021, Junta de Andalucía, Spain, Grant P08-CVI-00603, and EU Research Contract DEER FP7-ENV-2007-1. CIBER Fisiopatología de la Obesidad y Nutrición is an initiative of the Instituto de Salud Carlos III.

*V.M.N. and F.R.-P. contributed equally to this study and should be considered as joint first authors.

The authors declare no competing financial interests.

Correspondence should be addressed to either Víctor M. Navarro or Manuel Tena-Sempere, Department of Cell Biology, Physiology and Immunology, University of Córdoba, 14004 Córdoba, Spain, E-mail: nalovic@gmail.com or fi1tesem@uco.es.

DOI:10.1523/JNEUROSCI.4288-11.2012

Copyright $\odot 2012$ the authors $\quad 0270-6474 / 12 / 322388-10 \$ 15.00 / 0$
}

of NK3R agonists on luteinizing hormone (LH) secretion (Amstalden et al., 2010; Billings et al., 2010; Ramaswamy et al., 2010; Wakabayashi et al., 2010; Navarro et al., 2011a). Mounting evidence suggests that this action occurs within the arcuate nucleus (ARC), through the regulation of the release of kisspeptins, encoded by Kiss1 (Ramaswamy et al., 2010; Navarro et al., 2011a). Indeed, NKB (and dynorphin) are expressed in Kiss1 neurons in the ARC, where they may act through recurrent collaterals to shape the pulsatile activity of those neurons (Navarro and TenaSempere, 2011).

Puberty is a key developmental period when reproductive capacity is achieved and sexual maturation is completed (Parent et al., 2003; Ojeda and Skinner, 2006; Ojeda et al., 2010). These events are centrally driven by the heightening of the neurosecretory activity of gonadotropin-releasing hormone $(\mathrm{GnRH})$ neurons (Ojeda and Skinner, 2006). Compelling evidence suggests that kisspeptin signaling plays a crucial role in this process (Roa et al., 2008; Oakley et al., 2009). In support of this concept, we can observe the following: (1) absence of kisspeptin signaling prevents puberty and leads to infertility in humans and mice (Oakley et al., 2009); (2) hypothalamic Kiss1 expression and the ability of kisspeptin to induce gonadotropin secretion increases over puberty in rodents (Navarro and Tena-Sempere, 2011); and (3) transient antagonism of kisspeptin signaling delays puberty onset 
in rats (Pineda et al., 2010), while chronic administration of kisspeptin advances puberty onset (Navarro et al., 2004b). However, despite the proposed interplay between kisspeptins and NKB in the control of GnRH secretion in adulthood, the potential roles of NKB signaling in the timing of puberty remains virtually unexplored.

Reproduction, as an energy-demanding process, is sensitive to metabolic signals (Fernandez-Fernandez et al., 2006). Hence, sensing the metabolic status and transmitting this information to the hypothalamic reproductive centers are tightly regulated phenomena. Indeed, peripheral and central signals closely interplay to shut down the reproductive axis during energy-deficient periods. The hypothalamic Kiss1 system has been proposed to convey these inputs onto GnRH neurons (Castellano et al., 2010). Thus, a negative energy balance decreases Kiss 1/kisspeptin expression at the hypothalamus, whereas exogenous administration of kisspeptin rescues puberty and reproductive function in undernourished animals (Castellano et al., 2010). However, the role of NKB signaling in the metabolic control of puberty is yet to be characterized. Of note, a recent study documented inhibition of ARC $\mathrm{NKB}$ expression following caloric restriction in adult rats (True et al., 2011).

In this context, we hypothesized that $\mathrm{NKB}$ and NK3R are involved in the timing of puberty in the female rat. We present herein the first evidence of the stimulatory role of NKB signaling in female puberty and document its modulation by conditions of metabolic stress, such as undernutrition, which are known to perturb normal pubertal maturation.

\section{Materials and Methods}

\section{Animals and drugs}

Female Wistar rats were bred in the vivarium at the University of Córdoba, in Córdoba, Spain. The animals were maintained under constant conditions of light (14 h of light, from 7:00 A.M.) and temperature $\left(22^{\circ} \mathrm{C}\right)$. They were weaned at $21 \mathrm{~d}$ postpartum, when they were housed in groups of five rats per cage with free access to standard rat chow and tap water, until used in specific experiments. For hormonal tests involving intracerebroventricular cannulation, the rats were caged individually from the day before cannulae implantation until termination of experiments. Correct positioning of the cannulae was checked by visual inspection (to exclude animals showing obvious displacement or detachment) and confirmed at necropsy. Experimental procedures were approved by the University of Córdoba Ethical Committee for Animal Experimentation and were conducted in accordance with the European Union norms for the care and use of experimental animals. The NK3R agonist (senktide) and antagonist (SB222200) were purchased from Sigma Chemical and Tocris Bioscience, respectively. Doses of senktide and SB222200 were selected/adapted on the basis of previous studies (SandovalGuzmán and Rance, 2004; Ramaswamy et al., 2010; Navarro et al., 2011a).

\section{Experimental Design}

Developmental regulation of hypothalamic Tac2 and Tacr 3 expression (Experiments 1-3). In Experiment 1, analysis of hypothalamic expression of Tac2 (rodent ortholog of TAC3) and Tacr3 (ortholog of TACR3) mRNAs was conducted at different stages of postnatal development. Hypothalamic samples ( $n=4$ /group) were obtained from female rats at postnatal day 1 (P1), P7, P10, P15, P20, P24, P30, P36, and P60, corresponding to the neonatal (P1), infantile (P7, P10, and P15), juvenile/prepubertal (P20 and P24), pubertal (P30 and P36), and adult (P60) stages of postnatal development; the latter (i.e., adult female rats) were checked for regular estrous cyclicity by monitoring vaginal smears and were sampled in the morning of the diestrous phase of the cycle. In Experiment 2, the neuroanatomical distribution of Tac2 and Tacr3 expression was compared between late-infantile/prepubertal and pubertal female rats. First, we mapped the distribution of Tac2 and Tacr3 mRNAs in the brain of intact female rats at the transition between the late-infantile and prepubertal stages of maturation (P20 rats) [i.e., at the middle of the transitional phase between low (P15) and high (P24) expression in both genes observed in Experiment 1]. Second, we mapped the expression of Tac2 and Tacr3 in pubertal (P36) female rats. Brains were immediately removed, gradually frozen on dry ice, and stored at $-80^{\circ} \mathrm{C}$ until they were sectioned on a cryostat, thaw mounted, and stored at $-80^{\circ} \mathrm{C}$ until used for in situ hybridization (ISH). Trunk blood samples for hormone measurements were also collected at the time of decapitation. In Experiment 3, the hypothalamic nuclei comprising the majority of the expression of Kiss1 [ARC and anteroventral periventricular nucleus (AVPV)], Tac2 [ARC and lateral hypothalamic area (LHA)], and Tacr3 [ARC, paraventricular nucleus (PVN), and LHA] were selectively targeted, and the expression of Tac2 and Tacr3 genes were quantitatively assayed and compared between 20 - and 36-d-old female rats.

Responses to NKB agonist and antagonist in prepubertal female rats (Experiments 4 and 5). In Experiment 4, we assessed the ability of the NK3R agonist, senktide, to influence $\mathrm{LH}$ secretion in prepubertal rats. To this end, central (intracerebroventricular) administration of senktide into the lateral cerebral ventricle was conducted at two developmental stages: infantile (P10) and juvenile (P25) female rats ( $n=10 /$ group). For comparative purposes, adult (P60) females in diestrus-1 $(n=10$ rats/ group) were also tested, as senktide has been previously described to elicit a potent secretory response of LH (Navarro et al., 2011a). A dose of 600 $\mathrm{pmol} / 10 \mu \mathrm{l}$ per rat was injected on the basis of previous studies (Navarro et al., 2011a). Briefly, animals were implanted with intracerebroventricular cannulae; to allow delivery of senktide into the lateral ventricle, the cannulae were lowered to a depth of $3 \mathrm{~mm}$ beneath the surface of the skull; the insert point was $1 \mathrm{~mm}$ posterior and $1.2 \mathrm{~mm}$ lateral to bregma, as described in detail previously (Navarro et al., 2004b). Animals were bled through jugular venipuncture before senktide injection ( $0 \mathrm{~min})$, and 20 and 60 min after injection. Animals injected with vehicle (physiological saline, $0.9 \% \mathrm{NaCl}$ ) served as controls. To note, 10 -d-old rats were only bled $20 \mathrm{~min}$ after senktide injection, due to a reduced body size that prevented us from also sampling at $60 \mathrm{~min}$. Blood was collected, and serum samples were separated by centrifugation at $1600 \times g$ for $20 \mathrm{~min}$ and stored at $-20^{\circ} \mathrm{C}$ until use for hormone determinations.

As a complement to the above acute study, in Experiment 5 the effects of chronic central administration of the NK3R antagonist, SB222200, on puberty onset in immature female rats were assessed. The treatment protocol was set following our previous studies of the pubertal effects of kisspeptin antagonism (Pineda et al., 2010). The ability of SB222200 to antagonize NKB action has been recently tested in the monkey (Ramaswamy et al., 2010) and confirmed by the blockade of the NKB-dependent activation of Kiss1 neurons in the mouse (Navarro et al., 2011b). Central administration of the antagonist in the lateral cerebral ventricle was conducted as described previously (Navarro et al., 2004b), following protocols of cannulation similar to those of Experiment 4. Injection of SB222200 ( $3 \mathrm{nmol}$ ) was initiated at P28 and repeated every $12 \mathrm{~h}$ until P36 $(n=11)$. An additional group of females injected with vehicle $(n=12)$ was carried in parallel. In all animals, body weight and vaginal opening (VO) were monitored daily. At the end of treatment, all the animals were killed by decapitation 15 min after the last injection of SB222200. Trunk blood was collected, and the uteri were dissected out of the surrounding fat and their dry weights recorded.

Metabolic control of NKB system at puberty (Experiments 6-8). As continuation of the previous studies, this set of experiments was conducted to evaluate whether expression and function of NKB signaling is influenced by metabolic signals at puberty. In Experiment 6, pubertal female rats $(n=10)$ were subjected to $48 \mathrm{~h}$ of fasting. A pair-aged group of animals fed ad libitum was used as control. At the end of the experiment (P36), the animals were killed by decapitation, and brains and blood were collected as described above. The brains were processed by ISH for Kiss 1, Tac2, and Tacr3 genes in the same hypothalamic nuclei as in Experiment 2. In Experiment 7, the ability of senktide to acutely induce/modulate LH secretion under conditions of negative energy balance was assessed in pubertal (P36) female rats $(n=10)$ subjected to the same protocol of $48 \mathrm{~h}$ fasting used in Experiment 6 . As described in Experiment 4, animals were bled before senktide injection $(0 \mathrm{~min})$, and 20 and $60 \mathrm{~min}$ after central 
(intracerebroventricular) injection of a 600 pmol bolus of senktide; animals injected with vehicle served as controls. For comparative purposes, similar protocols of intracerebroventricular injection and blood sampling following administration of vehicle or $600 \mathrm{pmol}$ of senktide were implemented in additional groups of pubertal (P36) female rats $(n=10)$ fed ad libitum. Finally, in Experiment 8, we monitored the effects of repeated central administration of NKB agonist, senktide, on puberty onset in rats subjected to persistent caloric restriction. A protocol of $30 \%$ restriction in daily food intake was applied to immature female rats, staring on P23 postpartum, as this has been shown to prevent normal occurrence of $\mathrm{VO}$ and pubertal progression in female rats (Castellano et al., 2005). Daily repeated intracerebroventricular injection of senktide was implemented between P30 and P37 in food-restricted females $(n=$ 11), following previously published protocols (Castellano et al., 2005). The treatment regimen was set at a dose of $600 \mathrm{pmol}$ of senktide per animal in $10 \mu \mathrm{l}$, every $12 \mathrm{~h}$. Pair-aged females $(n=12)$, at $30 \%$ food restriction, injected with vehicle served as controls. Body weight and VO were monitored daily as described in Experiment 5. At the end of treatment (P37), the animals were killed by decapitation, 20 min after the last injection of senktide (or vehicle), and trunk blood was collected. To determine the normal date of vaginal opening in animals fed ad libitum, an additional group of females $(n=20)$ without food restriction were maintained on daily inspection of canalization of the vagina up to P37.

\section{Tissue preparation}

Blood was centrifuged to isolate the serum, which was stored at $-20^{\circ} \mathrm{C}$ until hormone measurements. Uteri were removed and weighed to provide an indirect marker of plasma $\mathrm{E}_{2}$ levels (and their biological effect). Brains were removed for ISH, frozen on dry ice, and then stored at $-80^{\circ} \mathrm{C}$ until sectioned. Five sets of $20 \mu \mathrm{m}$ sections in the coronal plane were cut on a cryostat (from the diagonal band of Broca to the mammillary bodies), thaw mounted onto SuperFrost Plus slides (VWR Scientific), and stored at $-80^{\circ} \mathrm{C}$. A single set was used for each in situ hybridization assay (adjacent sections $100 \mu \mathrm{m}$ apart).

\section{Radioimmunoassay for $\mathrm{LH}$}

Serum LH levels were measured in $50 \mu \mathrm{l}$ samples with double-antibody RIA kits supplied by the National Institutes of Health (Dr. A. F. Parlow, National Hormone and Peptide Program, Torrance, CA). Rat LH-I-10 was labeled with ${ }^{125} \mathrm{I}$ using IODO-GEN tubes, following the instructions of the manufacturer (Pierce). Hormone concentrations were expressed with the reference preparation LH-RP-3 as a standard. Intraassay and interassay coefficients of variation were $<8$ and $10 \%$, respectively. The sensitivity of the assay was $5 \mathrm{pg} / \mathrm{tube}$.

\section{Semiquantitative RT-PCR of Tac2 and Tacr3 mRNAs}

Real-time RT-PCR was performed in whole hypothalamic samples with the iCycler iQ Real-Time PCR detection system (Bio-Rad Laboratories). In detail, Tac2 and Tacr3 mRNA levels were assayed in samples from different stages of postnatal development in females (1-, 7-, 10-, 15-, 20-, 24-, 30-, 36-, and 60-d-old rats; the latter were monitored for regular estrous cyclicity and sampled in the diestrous phase of the ovarian cycle). For each target, RT-PCR amplification was routinely conducted with two different sets of primers, which were generated on the basis of the published sequences of the rat Tac2 gene (NM_019162.1), sequences: 153-171 (sense) and 299-319 (antisense); and the Tacr3 gene (NM_017053.1) sequences: 862-881 (sense) and 985-1008 (antisense). The synthesized cDNAs were further amplified (1:10) in triplicate by PCR with SYBR Green I as fluorescent dye and $1 \times$ iQ Supermix containing $50 \mathrm{~mm} \mathrm{KCl}, 20 \mathrm{~mm}$ Tris-HCl, $0.2 \mathrm{~mm}$ deoxy-NTPs, $3 \mathrm{~mm} \mathrm{MgCl}_{2}$, and $2.5 \mathrm{U}$ iTaq DNA polymerase (Bio-Rad Laboratories) in a final volume of $25 \mu \mathrm{l}$. The PCR cycling conditions were as follows: initial denaturation and enzyme activation at $95^{\circ} \mathrm{C}$ for $5 \mathrm{~min}$; followed by 40 cycles of denaturation at $95^{\circ} \mathrm{C}$ for $30 \mathrm{~s}$; annealing at $57^{\circ} \mathrm{C}($ Tac2 $), 53^{\circ} \mathrm{C}($ Tacr 3$)$, or $58^{\circ} \mathrm{C}$ (RP-S11) for $30 \mathrm{~s}$; and extension at $72^{\circ} \mathrm{C}$ for $10 \mathrm{~s}$. Product purity was confirmed by dissociation curves and random agarose gel electrophoresis. No template controls were included in all assays, yielding no consistent amplification. Calculation of the relative expression levels of the target mRNAs was conducted based on the cycle threshold $\left(\mathrm{C}_{\mathrm{t}}\right)$ method (Navarro et al., 2004a). The $C_{t}$ for each sample was calculated using
iCycler iQ real-time PCR detection system software with an automatic fluorescence threshold setting. Accordingly, the fold expression of target mRNAs over reference values was calculated by the equation $1+\mathrm{e}^{-\Delta \Delta \mathrm{Ct}}$ where $\Delta \mathrm{C}_{\mathrm{t}}$ is determined by subtracting the corresponding RP-S11 $\mathrm{C}_{\mathrm{t}}$ value (internal control) from the specific $\mathrm{C}_{\mathrm{t}}$ of the target (Tac2 or Tacr3), and $\Delta \Delta \mathrm{C}_{\mathrm{t}}$ is obtained by subtracting the $\Delta \mathrm{C}_{\mathrm{t}}$ of each experimental sample from that of the reference sample (taken as reference value 100). No significant differences in $\mathrm{C}_{\mathrm{t}}$ values were observed for RP-S11 between the treatment groups.

Detection of Kiss1, Tac2, and Tacr3 mRNAs probe generation The probes used for detection of Kiss1, Tac2, and Tacr3 mRNAs have been described previously (Navarro et al., 2009). Sense probes for every transcript were used as controls for the specificity of the ISH procedures, which are outlined below.

\section{Single-label in situ hybridization of Kiss1, Tac2, and Tacr3} mRNAs

Kiss1, Tac2, and Tacr3 mRNA sense and antisense probes were transcribed with T7 or T3 polymerase (Fermentas), as described previously (Navarro et al., 2009). Briefly, radiolabeled probes were synthesized in vitro by inclusion of the following ingredients in a volume of $20 \mu \mathrm{l}: 250 \mathrm{Ci}$ $\left[{ }^{33} \mathrm{P}\right]$ UTP (PerkinElmer Life and Analytical Sciences); $1 \mu \mathrm{g}$ of PCR product; 0.5 mM each ATP, CTP, and GTP; and $40 \mathrm{U}$ of polymerase. Residual DNA was digested with $4 \mathrm{U}$ of DNase (Ambion), and the DNase reaction was terminated by addition of $2 \mu \mathrm{l}$ of $0.5 \mathrm{M}$ EDTA, $\mathrm{pH}$ 8.0. The riboprobes were separated from unincorporated nucleotides with NucAway Spin Columns (Ambion). Slides with mouse hypothalamic sections from the different experimental groups were processed as reported previously (Cunningham et al., 2002; Gottsch et al., 2004).

\section{Quantification and analysis of Kiss1, Tac2, and Tacr3 mRNAs} Brain sections were analyzed unilaterally. Slides from all of the animals were assigned a random three-letter code, alphabetized, and read under dark-field illumination with custom-designed software designed to count the total number of cells and the number of silver grains (corresponding to radio-labeled Kiss1, Tac2, and Tacr3 mRNA) over each cell (Chowen et al., 1990). Data are presented as total mRNA content, depicting the number of cells $\times$ grains per cell within the coronal sections containing the hypothalamic nucleus studied for each set, not the total mRNA in this specific nucleus. The starting and ending points of quantification were determined according to the atlas of Paxinos and Watson (2001).

\section{Statistical analysis}

All data are expressed as the mean \pm SEM for each group. In addition, when appropriate, integrated LH secretory responses were expressed as the area under the curve (AUC), calculated following the trapezoidal rule (Protter and Morrey, 1964), over a 60 min period after the administration of senktide. One-way ANOVA followed by Tukey's post hoc test and Student's $t$ test were used to assess variation among experimental groups. Significance level was set at $p \leq 0.05$. All analyses were performed with GraphPad Prism.

\section{Results}

\section{Tac2 and Tacr3 mRNA levels in rat hypothalamus during development}

The profiles of hypothalamic expression of Tac2 and Tacr3 mRNAs, rat orthologs of human TAC3 and TACR3, were evaluated in hypothalamic samples from female rats at different stages of postnatal development, from the neonatal period to adulthood. Stages of postnatal maturation were defined on the basis of previous references (Ojeda and Skinner, 2006), and timing of puberty onset in the female rat was assessed following consensus criteria and recording of external signs of reproductive maturation, such as vaginal opening (Ojeda and Skinner, 2006). Persistent expression of Tac2 and Tacr3 mRNAs was detected in the hypothalamus by means of real-time RT-PCR along postnatal maturation. Expression of Tac2 and Tacr 3 was virtually undetect- 

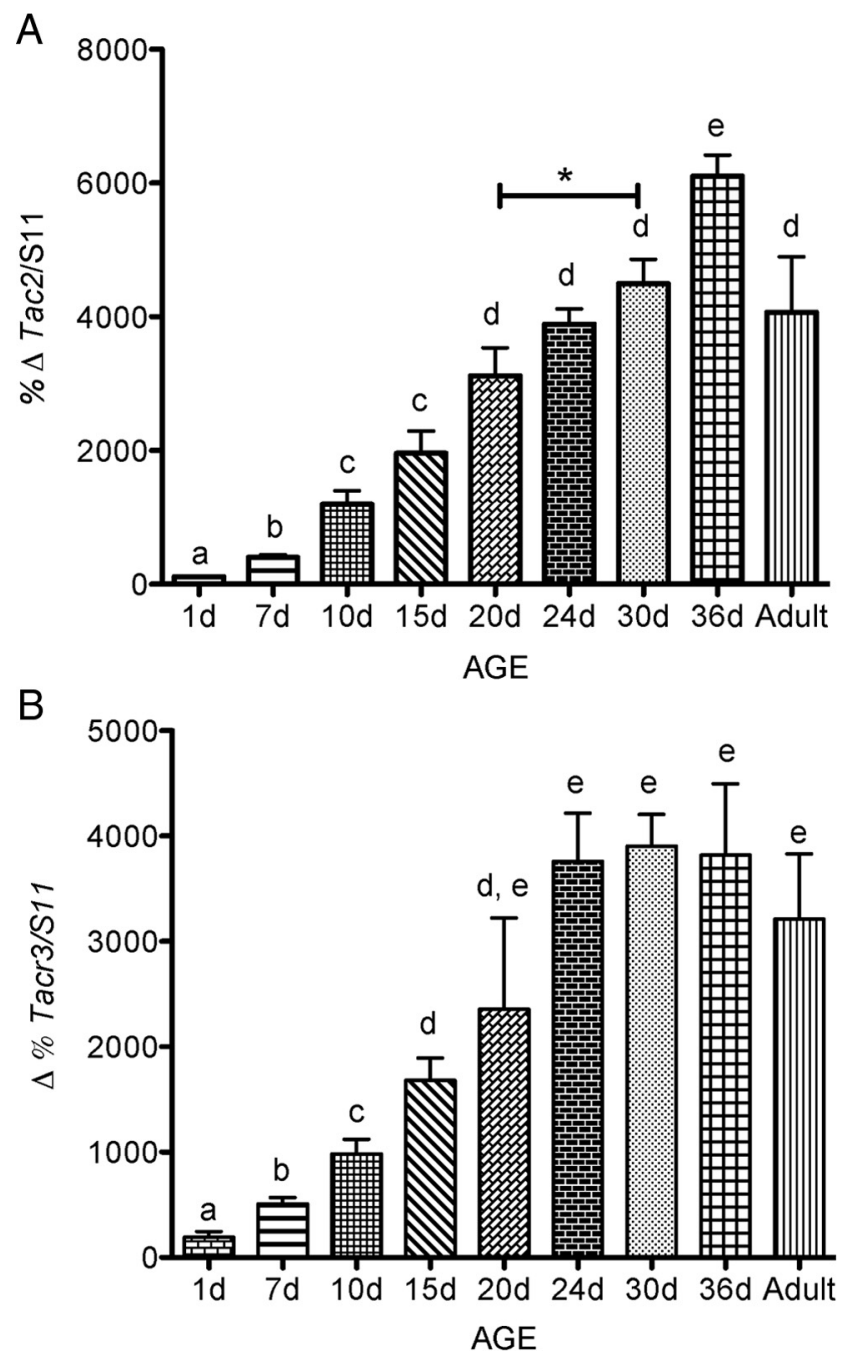

Figure 1. $\quad \boldsymbol{A}, \boldsymbol{B}$, Developmental profiles in the expression of $\operatorname{Tac} 2(\boldsymbol{A})$ and $\operatorname{Tacr} 3(\boldsymbol{B})$ in the hypothalamus of the female rat. Values represent the percentage of the lowest value (100\%) measured by real-time RT-PCR and normalized to the S11 ribosomal protein mRNA. Groups with different superscript letters and asterisks are statistically different from one another ( $p<0.05$, by one-way ANOVA followed by Student-Newman-Keuls multiple range test and unpaired Student's $t$ test).

able in neonatal females but increased progressively over the infantile (P7, P10, and P15) and juvenile/prepubertal periods (P20, $\mathrm{P} 24$, and P30) of postnatal maturation. Maximal expression was reached at the time of puberty onset (P36) for Tac2, whereas peak Tacr3 levels plateaued during the peripubertal transition (Fig. 1). This was followed by a decreasing trend in the expression of both genes in adult (diestrus-1) animals, which was statistically significant for Tac2. Nonetheless, hypothalamic mRNA levels of Tac2 and Tacr 3 in adult females remained higher than in infantile rats.

\section{Neuronal mapping of Tac 2 and Tacr 3 expression in prepubertal versus peripubertal rats}

The neuroanatomical distribution of Tac2 and Tacr3 mRNA was assessed in medial coronal sections of the female rat brain at two representative stages of postnatal maturation by ISH. P20 was chosen on the basis of results obtained in Experiment 1 as a period of transition between low (infantile) and high (late juvenile/prepubertal) expression of both genes. Likewise, P36 was selected as the representative pubertal stage with maximal levels of Tac2 and Tacr 3 mRNAs. Tac2 expression was broadly detected across brain sections with similar distribution in both ages. Tac2 transcripts were predominantly present in cortical and hippocampal areas [somatosensory area 1 (SS1), parietal region 4 (PTL4), and Ammon's horn (CA)], supraoptic area, and lateral and medial basal hypothalamic nuclei (LHA and ARC). Of note, P36 animals showed wider expression in the basal hypothalamus with detectable expression at the ventromedial nucleus, which was absent in P20 animals (Fig. 2). Tacr3 mRNA showed a scattered and differential distribution with more abundant expression at the amygdala (basolateral amygdalar nucleus and basomedial amygdalar nucleus) and LHA in prepubertal animals. Additionally, similar to Tac2 expression, Tacr3 mRNA was equally detected in both groups within cortical and hippocampal areas (SS4, PTL4, and CA) and medial basal hypothalamus (periventricular hypothalamic nucleus and ARC) (Fig. 2).

\section{Quantitative changes of expression of Kiss1, Tac2, and Tacr3 over pubertal maturation}

The expression levels of Kiss1, Tac2, and Tacr3 genes were quantified in representative hypothalamic nuclei, selected on the basis of the prominent presence of these targets (see neuronal mapping results), comparing late-infantile (P20) and peripubertal (P36) animals. Kiss 1 expression remained unchanged in the ARC during this transition; however, it increased significantly in the AVPV (Fig. $3 A,{ }^{\star} p<0.01$ ). Tac2 mRNA levels did not show any significant change in any of the nuclei assessed (ARC and LHA) during the pubertal transition (Fig. 3B). In contrast, Tacr3 expression significantly augmented on $\mathrm{P} 36$ in the ARC, but not in the PVN or LHA (Fig. $3 C,{ }^{\star} p<0.05$ ).

\section{Effects of NKB agonist, senktide, on LH secretion in prepubertal and adult female rats}

The NKB agonist, senktide, induced a robust increase in serum LH levels $20 \mathrm{~min}$ after central (intracerebroventricular) injection, in both prepubertal (P25) $(p<0.01$; Fig. $4 A)$ and adult female rats on diestrus- $1(p<0.01$; Fig. $4 B)$; the latter is in keeping with recent reports (Navarro et al., 2011a). At both ages, LH levels remained elevated at $60 \mathrm{~min}$ after intracerebroventricular administration of senktide. Accordingly, the overall integrated secretory response (calculated as the AUC over a 60 min study period) showed a significant elevation in both age groups (prepubertal: vehicle $=31.0 \pm 6.2 \mathrm{ng} / \mathrm{ml}$ per $60 \mathrm{~min}$ vs senktide $=113.7 \pm$ 21.7, $p<0.01$; adult/diestrus- 1 : vehicle $=52.2 \pm 10.1 \mathrm{ng} / \mathrm{ml}$ per 60 min vs senktide $=145.2 \pm 21.1, p<0.01$ ).

In addition, the stimulatory effects of senktide on LH secretion were also detected at an earlier age point (i.e., during the early infantile period). Thus, 10 -d-old female rats displayed a robust fivefold increase of the circulating LH levels at 20 min after intracerebroventricular injection of senktide (vehicle alone: $0.32 \pm 0.03 \mathrm{ng} / \mathrm{ml}$; vs senktide: $1.69 \pm 0.13, p<0.01$ ). Of note, because of low body size, no sampling was conducted at this age 60 min after senktide administration.

\section{Effects of central infusion of an NK3R antagonist on puberty onset}

On the basis of the stimulatory effects of senktide on LH secretion in prepubertal female rats, we next sought to determine whether chronic blockage of NK3R signaling would delay the normal onset of puberty. To this end, we tested the effect of a chronic (but intermittent) infusion of the antagonist of the NK3R, SB222200, on several markers of pubertal maturation. A model of repeated intracerebral (lateral ventricle) injection of the antagonist was selected to limit its effects to the brain. Following analogous protocols of kisspeptin antagonism (Pineda et al., 2010), pharmaco- 


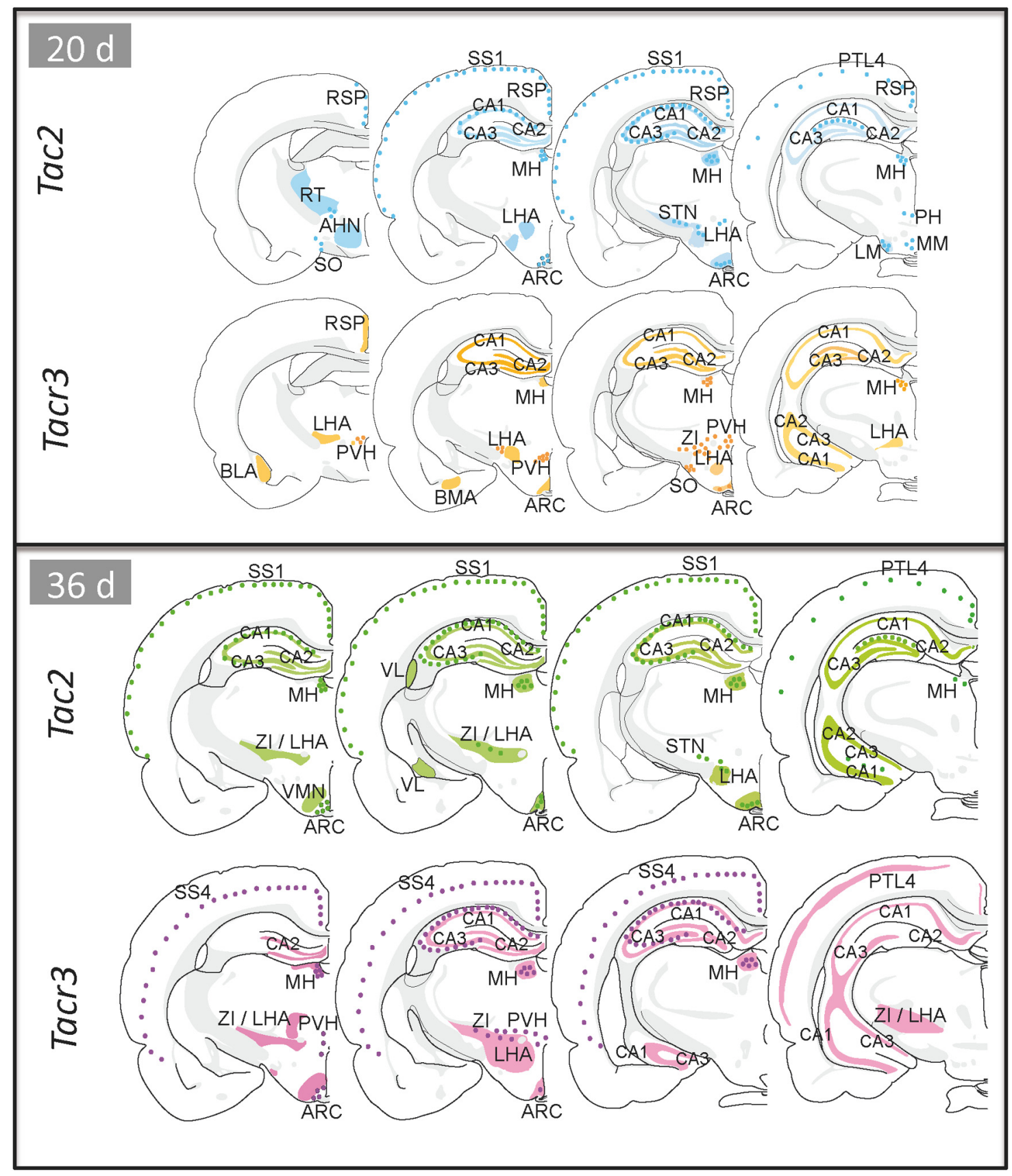

Figure 2. Schematic representation of the distribution of Tac2 and Tacr3 mRNAs in the brain of late-infantile (P20) and pubertal (P36) female rats. AHN, Anterior hypothalamic nucleus; BLA, basolateral amygdalar nucleus; BMA, basomedial amygdalar nucleus; LM, lateral mammilary nucleus; LV, lateral ventricle; MH, medial habenula; PH, posterior hypothalamic nucleus; PVH, periventricular hypothalamic nucleus; RSP, retroesplenial area; RT, reticular nucleus thalamus; SO, supraoptic nucleus; STN, subthalamic nucleus; Zl, zona incerta.

logical treatments were administered between P28 and P36, and the progression of puberty was monitored. As an external index of puberty onset, $\mathrm{VO}$ (defined as complete canalization of the vagina) was monitored daily. Such a marker was selected as it has been conventionally considered a reliable external sign of puberty (Navarro et al., 2004b). Infusion of NK3R antagonist did not alter body weight, food intake (data not shown), or uterine weight over the study period (Fig. 5). Nevertheless, repeated central administration of SB222200 to peripubertal female rats evoked a moderate delay in the overall timing of puberty onset. Thus, the percentage of VO was persistently lower in the SB222200-injected group starting at day 32 , and by day 35 , when nearly $80 \%$ of vehicle-treated females displayed VO, only $50 \%$ of the antagonist-injected animals did (Fig. 5). Yet, the antagonist group tended to catch up, and by day 36 no differences in terms of the percentage of $\mathrm{VO}$ were detected between groups. In addition, a decreasing trend in LH levels in the animals treated with the antagonist was observed at the end of the treatment (45\% reduction in mean values), although it did not reach statistical significance.

\section{Effects of $48 \mathrm{~h}$ fasting on hypothalamic expression of Kiss 1 , Tac2, and Tacr3}

To determine the effects of metabolic stress associated with negative energy balance on the hypothalamic expression of Kiss1, Tac2, and Tacr 3 genes, single-label ISH was performed brain sec- 

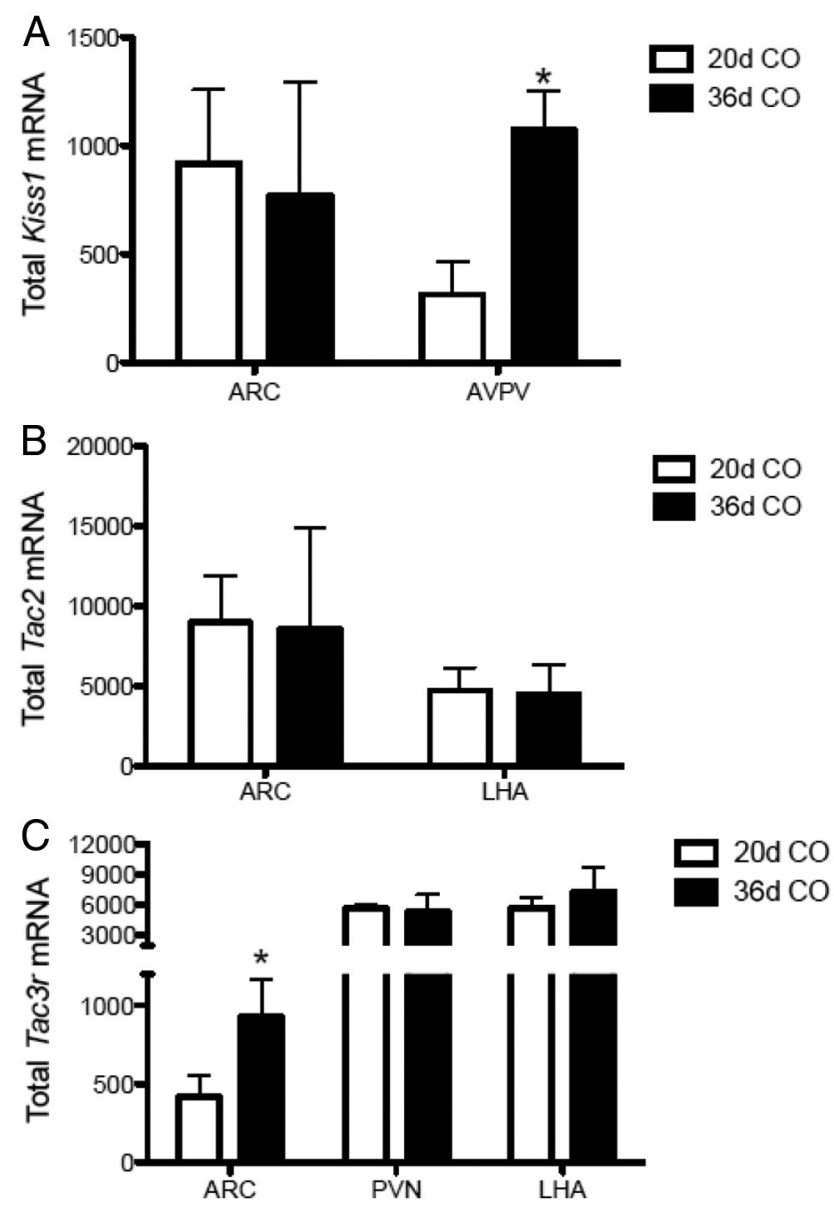

Figure 3. $\quad \boldsymbol{A}-\boldsymbol{C}$, Profile of expression of Kiss $7(\boldsymbol{A})$, $\operatorname{Tac2}(\boldsymbol{B})$, and $\operatorname{Tacr} 3(\boldsymbol{C})$ expression in specific hypothalamic nuclei of late-infantile (20-d-old) vs pubertal (36-d-old) female rats. Data are presented as total mRNA (number of cells $\times$ grains/cell) assessed by in situ hybridization. ${ }^{*} p<$ 0.05 , by unpaired Student's $t$ test within each nucleus.

A Prepubertal (25-d)

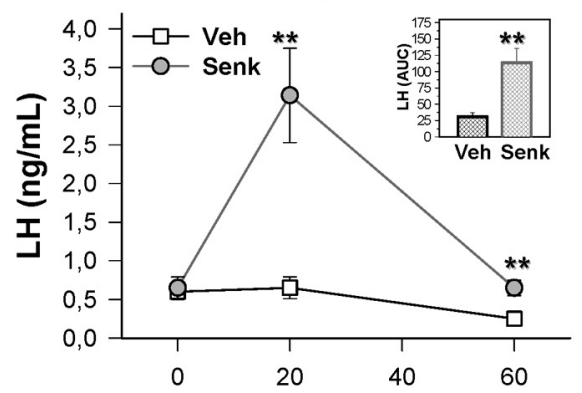

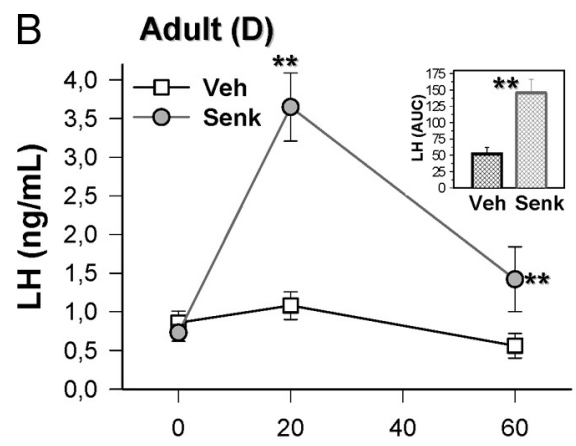

Figure 4. $\quad \boldsymbol{A}, \boldsymbol{B}$, Serum LH levels in prepubertal 25 -d-old $(\boldsymbol{A})$ and adult female rats in diestrus-1 $(\boldsymbol{B})$, at 0,20 , and 60 min after central intracerebroventricular administration of vehicle or $600 \mathrm{pmol} /$ rat senktide. In addition to the profiles of mean LH levels in the experimental groups, the integrated secretory responses, as the AUC over the study period (60 min), are shown (in the inset as a bar graph). ${ }^{* *} p<0.01$ versus corresponding vehicle-injected controls (one-way ANOVA followed by Student-Newman-Keuls multiple range test or unpaired Student's $t$ test; the latter for AUC data). Veh, Vehicle; Senk, senktide.

was statistically significant. Tacr3 expression was significantly inhibited in the ARC after $48 \mathrm{~h}$ of fasting $(p<0.05)$, but remained constant in the PVN and LHA (Fig. 6C).

\section{$\mathrm{LH}$ responses to the NKB agonist, senktide, under severe caloric restriction}

The role of NKB in the regulation of gonadotropin secretion under conditions of metabolic stress associated with negative energy balance was explored by assessing the LH-releasing effects of senktide in pubertal female rats after $48 \mathrm{~h}$ of fasting. In age-matched (P36) rats fed ad libitum, intracerebral injection of 600 pmol of senktide induced significant $\mathrm{LH}$ responses $(>2.2$-fold increase over vehicleinjected controls), at $20 \mathrm{~min}$ after injection $(p<0.01)$ (Fig. $7 A$ ), with $>65 \%$ elevation of LH AUC in response to senktide. In fasted animals, the ability of similar doses $(600 \mathrm{pmol} / \mathrm{rat}$, i.c.v. $)$ of senktide to elicit LH secretion in vivo was not only preserved, but notably enhanced, as evidenced by the following observations: (1) absolute LH levels at $20 \mathrm{~min}$ after senktide administration were twofold higher in fasted animals; (2) LH levels remained significantly elevated in fasted animals at $60 \mathrm{~min}$ after senktide injection in fasted, but not fed, females; and (3) integral LH response to senktide over a 60 min period (AUC) was twice as high in pubertal females submitted to prior $48 \mathrm{~h}$ fasting (Fig. $7 B$ ).

\section{Effects of senktide on puberty onset under conditions of severe caloric restriction}

The effects of senktide upon the pubertal activation of the reproductive axis were monitored in immature female rats in a model of puberty arrest due to $30 \%$ restriction in daily food intake, initiated on P23 (Castellano et al., 2005). Repeated injections of senktide, starting at $\mathrm{P} 30$, were administered into the lateral ventricle. Control females fed ad libitum were also daily monitored. This group displayed normal progression of puberty, as evidenced by $>85 \%$ of the animals having complete $\mathrm{VO}$ at P36, when mean the body weight was $87.45 \pm 1.59 \mathrm{~g}$. Chronic food restriction induced a significant reduction in body weight of $\sim 30 \%$ from controls (mean body weight on P37, $67.75 \pm 0.59 \mathrm{~g} ; n=12$ ). This regimen totally prevented normal puberty onset, as none of the vehicle-injected females submitted to undernutrition displayed VO by P37. In contrast, chronic intracerebroventricular administration of senktide ( $600 \mathrm{pmol} / 12 \mathrm{~h}$ ) between P30 and P37 to food-restricted females induced complete VO in 5 of 11 treated animals $(\sim 45 \%)$, without a significant change in terminal mean body weight compared with vehicle-injected, food-restricted females. Moreover, mean body weight in the subset of senktide-treated females displaying $\mathrm{VO}$ $(65.4 \pm 2.48 \mathrm{~g} ; n=5)$ was similar to that in animals from the same group without $\mathrm{VO}$ $(67.33 \pm 1.25 \mathrm{~g} ; n=6)$. Additionally, regardless of the presentation of $\mathrm{VO}$, serum $\mathrm{LH}$ levels at the end of the chronic treatments were significantly elevated in tions from pubertal (P36) female rats after $48 \mathrm{~h}$ of fasting. Our protocol of food deprivation induced a significant $(>25 \%)$ decrease of body weight (data not shown), which was associated with a dampening of hypothalamic Kiss $1 \mathrm{mRNA}$ levels in both the ARC $(p<0.05)$ and AVPV $(p<0.05)$ (Fig. 6A). Likewise, a decreasing trend in Tac2 mRNA levels was observed in the ARC and LHA of fasted animals (Fig. 6B), but neither of these changes senktide-injected females, which displayed a $>4.5$-fold increase over vehicle-injected animals at $20 \mathrm{~min}$ after the last intracerebroventricular injection (Fig. 8).

\section{Discussion}

Studies in humans and other mammalian species suggest that NKB-NK3R signaling plays a critical role in the control of repro- 

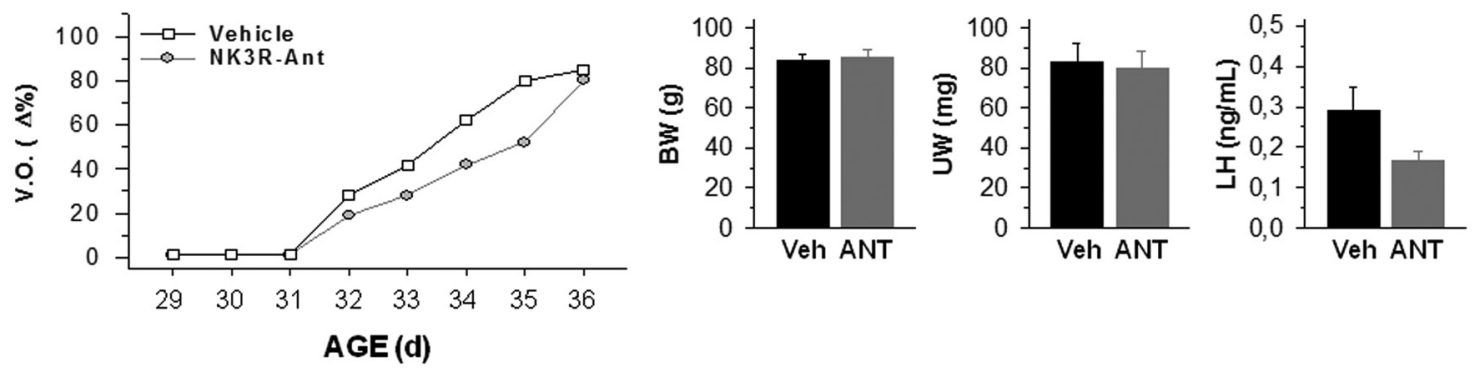

Figure 5. Compilation of indices of pubertal maturation recorded in immature female rats chronically intracerebroventricular injected $3 \mathrm{nmol}$ of SB222200 (NK3R antagonist) or vehicle. SB222200 was injected every $12 \mathrm{~h}$ between P28 and P36. Dates of vaginal opening (expressed as a percentage of the total number of animals per experimental group) are shown in the left panels. Data on body and uterus weights, as well as serum LH levels, in vehicle- and SB222200-injected animals are shown in the right panels. Values are the mean \pm SEM. Veh, Vehicle; ANT, antagonist; BW, body weight; UW, uterus weight.
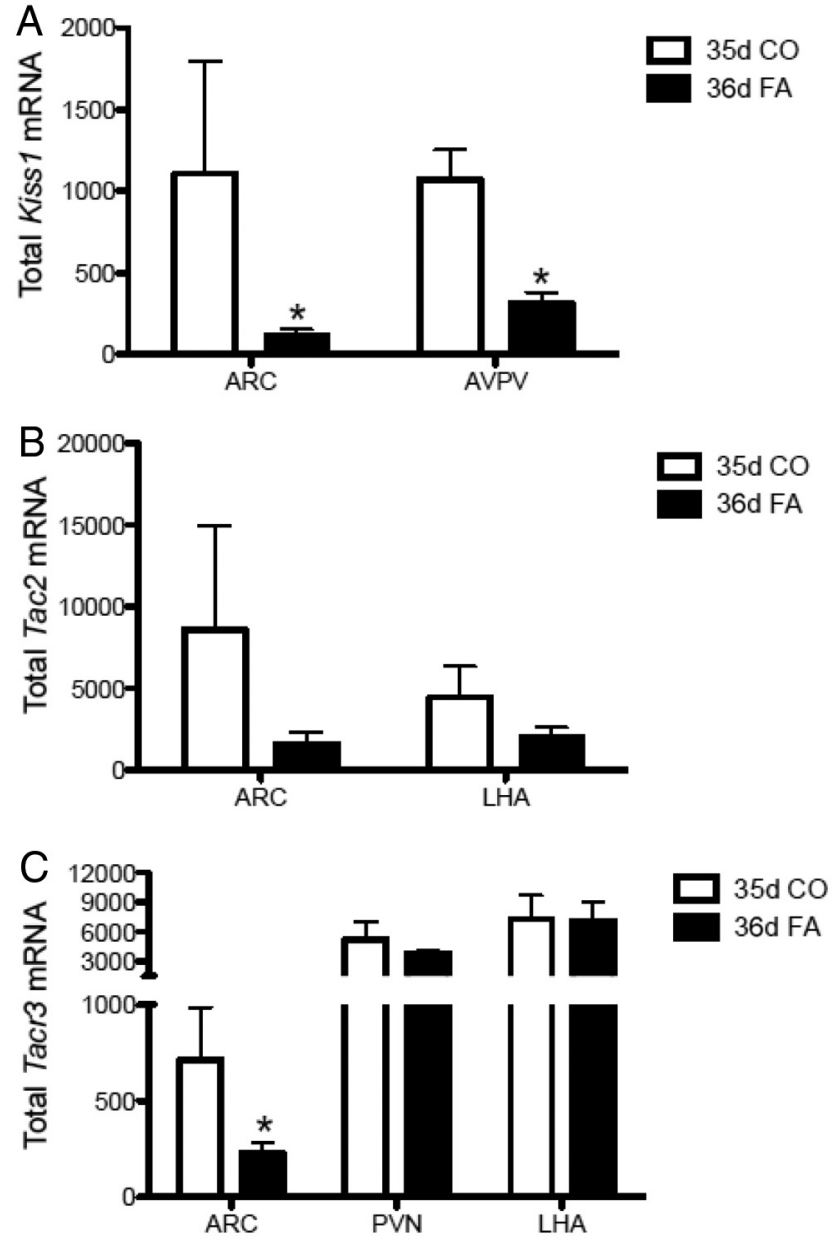

Figure 6. $\quad \boldsymbol{A}-\boldsymbol{C}$, Effect of $48 \mathrm{~h}$ fasting on the total mRNA levels of Kiss 1 ( $\boldsymbol{A})$, Tac2 (B), and Tacr3 $(C)$ in specific hypothalamic nuclei of pubertal (36-d-old) female rats. ${ }^{*} p<0.05$, by unpaired Student's $t$ test within each nucleus.

ductive function in adulthood, a function that appears to be mediated, at least partially, by its ability to autoregulate the activity of Kiss 1 neurons in the ARC (Lehman et al., 2010; Wakabayashi et al., 2010; Navarro et al., 2011a) and is dependent on preserved kisspeptin signaling (Ramaswamy et al., 2011; García-Galiano et al., 2012). Yet, the precise role of NKB and its receptor in sexual maturation, and their possible interaction with metabolic status, remain largely unexplored. To address the putative contribution of NKB signaling to the onset of puberty, we evaluated here the developmental regulation of the hypothalamic NKB/NK3R system, with special attention to the pubertal transition. Studies in

\section{A Pubertal(36-d)-FED}

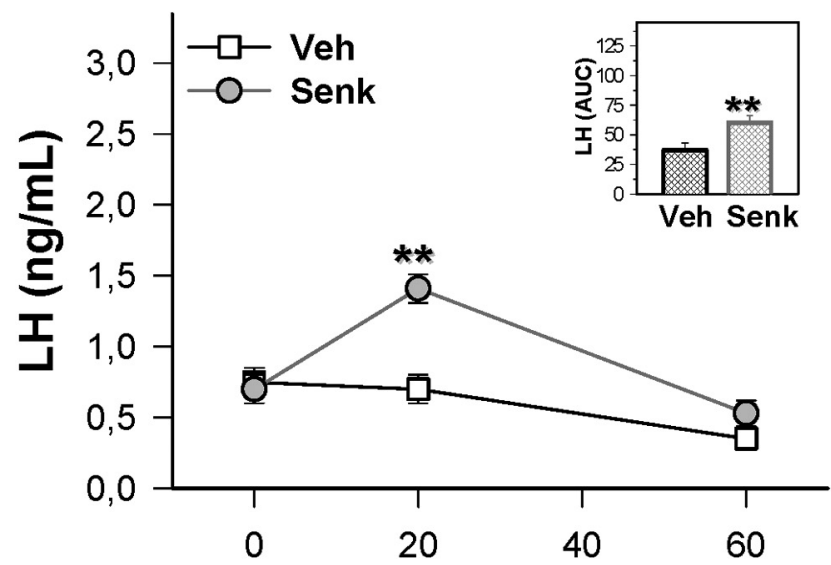

B Pubertal(36-d)-FASTING

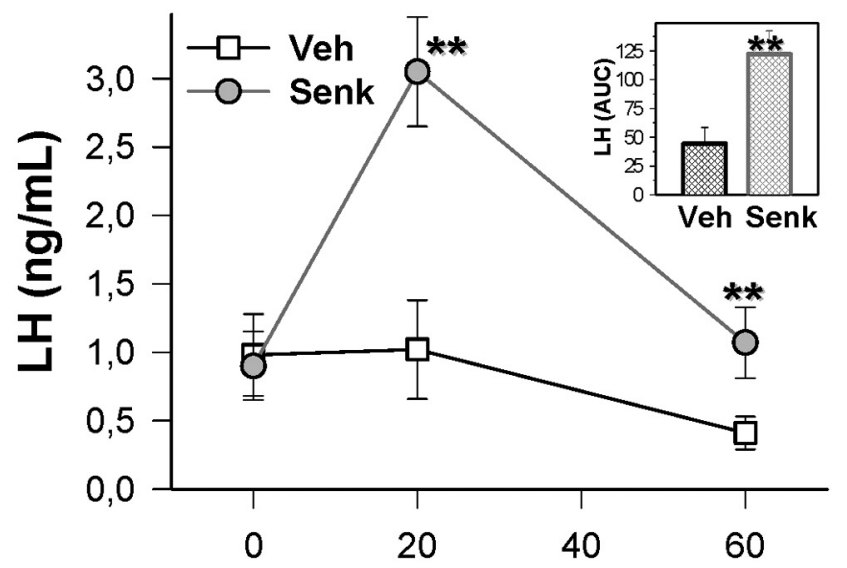

Figure 7. $\quad A, B$, Serum LH levels in pubertal 36-d-old female rats fed ad libitum $(\boldsymbol{A})$ or subjected to $48 \mathrm{~h}$ of fasting $(\boldsymbol{B})$ at 0,20 , and $60 \mathrm{~min}$ after central intracerebroventricular administration of vehicle or $600 \mathrm{pmol} /$ rat senktide in a $10 \mu \mathrm{l}$ volume. In addition to the profiles of mean LH levels in the experimental groups, the integrated secretory responses, reported as the AUC over the study period $(60 \mathrm{~min})$, are shown. ${ }^{* *} p<0.01$ versus corresponding vehicle-injected controls (one-way ANOVA followed by Student-Newman-Keuls multiple range test or unpaired Student's $t$ test; the latter for AUC data). Veh, Vehicle; Senk, senktide.

whole hypothalamic fragments, obtained serially along postnatal maturation, documented a striking profile of expression of Tac2 and Tacr3, with a progressive increase of both mRNAs from the neonatal/infantile to the peripubertal period, a profile that, compared with previously published data, appears to precede the elevation of hypothalamic Kiss1 mRNA that takes place between 

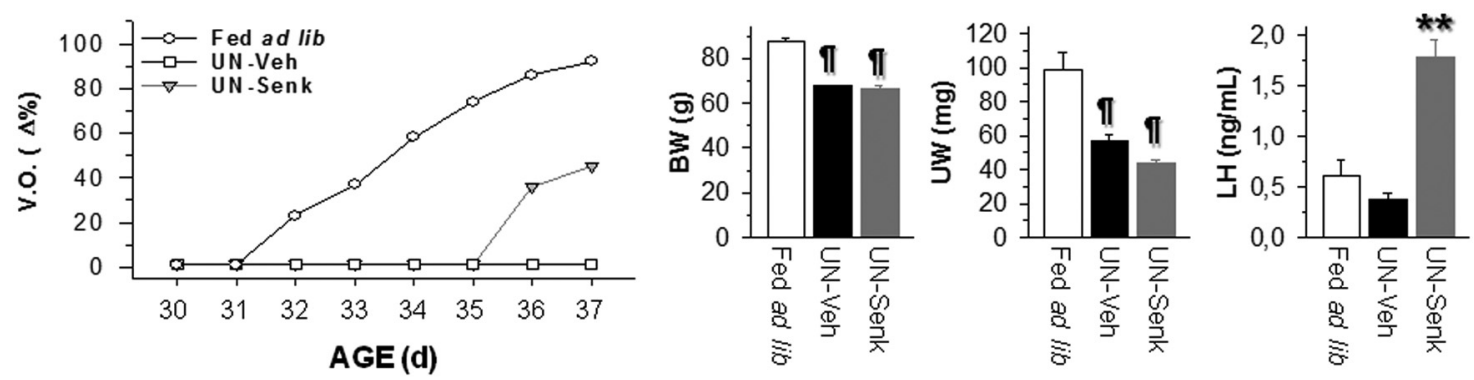

Figure 8. Compilation of indices of pubertal maturation recorded in peripubertal female rats subjected to a protocol of $30 \%$ restriction in daily food intake (UN; $70 \%$ food intake of controls), and chronically intracerebroventricularly injected with senktide $(600 \mathrm{pmol} / 12 \mathrm{~h}$ ) or vehicle between P30 and P37. For reference purposes, data from control females fed ad libitum and injected with vehicle are also shown. Dates of V0, expressed as the percentage over the total number of animals per each experimental group, are shown in the left panel. To note, although undernutrition prevented $\mathrm{V} 0$ in all vehicle-injected animals, senktide administration was able to restore canalization of the vagina in $\sim 50 \%$ of cases. Body and uterus weight records in the different experimental groups at the end of the treatment are presented in the right panels. In addition, senktide treatment significantly elevated serum LH levels. " $p<0.01$ vs controls fed $a d$ libitum; ${ }^{* *} p<0.01$ versus UN rats injected with vehicle (one-way ANOVA followed by Student-Newman-Keuls multiple range test). Veh, Vehicle; Senk, senktide; BW, body weight; UW, uterus weight.

P20 and P30 in the female rat (Navarro et al., 2004a). Furthermore, the rise of Tac2/Tacr3 expression described herein also seems to anticipate the sharp increase of kisspeptin immunoreactivity reported in the rostral periventricular area of the female mouse hypothalamus that occurs between P25 and P30 (Clarkson et al., 2009). Altogether, these observations are compatible with an eventual stimulatory role of NKB upon Kiss1/kisspeptin expression during (early) pubertal maturation. This possibility, which is yet to be experimentally tested, is in keeping with recent clinical observations suggesting that the NKB system may play a more prominent stimulatory role on the gonadotropic axis during early stages of sexual maturation (Gianetti et al., 2010).

To gain anatomical resolution, ISH studies for mapping the expression of Tac2 and Tacr3 genes were performed in prepubertal (P20) and pubertal (P36) animals, and detected moderate regional differences in the expression patterns of both genes between these two ages and also with the previously reported distribution in adults (Navarro et al., 2011a). Nonetheless, prominent expression of Tac2 and Tacr3 was observed in the ARC and LHA nuclei (and also the PVN, selectively for Tacr3) in both prepubertal and pubertal females. At the time of puberty, a notable increase in Tacr3 expression was detected by ISH exclusively in the ARC. Given the prominent expression of Tac2 in the ARC in 20- and 36-d-old females, it was anticipated that the increase in its expression between the infantile and juvenile periods (Fig. 1) would happen (mainly) in ARC neurons. However, our ISH analyses failed to detect an overt elevation of Tac2 levels between P20 and P36 in this nucleus. As possible explanation, Tac2 expression in the ARC might have reached rather high levels already on P20, which may obscure detection of further increases in this area. In addition, the potential contribution of increased expression of Tac2 in other hypothalamic regions cannot be excluded. On the other hand, Kiss1 expression did not increase significantly in the ARC during the pubertal transition, whereas it did in the AVPV, in good agreement with previous studies (Han et al., 2005; Takase et al., 2009; Bentsen et al., 2010; Gill et al., 2010). This would suggest that in the female rat most of the pubertal increase of Kiss 1 expression occurs mainly in AVPV, as recently proposed in the mouse (Gill et al., 2010). Nonetheless, it has been suggested that Kiss1 neurons in the ARC play an important role in puberty onset (Roa et al., 2011) - a contention indirectly supported also by the observations of increased Tacr3 expression in the ARC across the pubertal transition.

In agreement with a role for $\mathrm{NKB}$ in the timing of puberty, its agonist, senktide, robustly induced the release of LH in prepuber- tal females, consistent with the recently reported effects of this NKB agonist in juvenile monkeys (Ramaswamy et al., 2010) and our previous data in adult female rats (Navarro et al., 2011a). Of note, despite unambiguous hormonal responses at both ages, comparison of the magnitude of LH secretory peaks after senktide injection between P25 (juvenile) and P36 (peripubertal) females suggests a higher responsiveness to $\mathrm{NKB}$ stimulation during the prepubertal period, a phenomenon that may be indicative of the actual role of NKB signaling in the timing of puberty and whose physiological relevance is presently under investigation in our laboratory. Moreover, despite obvious reproductive immaturity, infantile females were also able to unambiguously respond to senktide in terms of $\mathrm{LH}$ secretion. This finding strongly suggests that the gonadotropic system becomes responsive to NKB stimulation well before the onset of puberty, so that low expression levels of Tac2 during the infantile period, as reported here, may play a role in preventing the precocious activation of the gonadotropic axis. Of note, a similar phenomenon (i.e., robust LH secretory responses during the infantile stage) has been described for kisspeptin stimulation in female rats (Castellano et al., 2006), an observation that is in line with the proposed mode of action of $\mathrm{NKB}$ as a modulator of kisspeptin secretion and, hence, actions in GnRH neurons (Navarro et al., 2009).

In turn, persistent blockade of NKB signaling during the pubertal transition did induce a modest but detectable delay in the timing of puberty. Noteworthy, the NK3R antagonist SB222200 used in our study has been shown to block direct NKB actions on mouse Kiss1 neuron (Navarro et al., 2011b) and to blunt in vivo LH responses to senktide in the monkey (Ramaswamy et al., 2010), thus confirming its efficacy and selectivity. However, its effect on puberty onset was not as effective in terms of pubertal perturbation as the chronic infusion of a kisspeptin antagonist, which resulted in a marked suppression of $\mathrm{VO}$ and sex organ weights at the expected age of puberty (Pineda et al., 2010). Altogether, the above observations suggest a discernible stimulatory role of NKB in the timing of puberty, which is less important than-and possibly subordinated to- that of kisspeptin signaling. Yet, it remains possible that more effective protocols of NKB antagonism (e.g., starting at earlier developmental stages) may have brought about more robust suppression of different indices of puberty.

Puberty is exquisitely sensitive to body energy status and metabolic cues that impinge on different central pathways to modulate GnRH secretory activity (Hill et al., 2008; Castellano et al., 
2010). Kiss1 neurons have been proposed as nodal elements for conveying metabolic information to reproductive centers at puberty, as evidenced by the impact of metabolic stress (e.g., acute fasting) on the hypothalamic expression of Kiss1/kisspeptins in pubertal animals, and the ability of exogenous kisspeptin to rescue puberty arrest due to metabolic distress (Castellano et al., 2005). Our present findings indicate that the NKB system is also subjected to metabolic regulation during puberty. First, the expression of Tacr3, and to a lesser extent Tac2, in the ARC was markedly suppressed in pubertal female rats by metabolic stress associated with $48 \mathrm{~h}$ fasting, as was Kiss 1 expression in the ARC and AVPV (see Fig. 6). Second, the LH responses to NKB agonist administration in pubertal (P36) rats were not only preserved but even augmented in fasting conditions, suggesting a possible sensitization of its stimulatory effects under conditions of negative energy balance; again, this is similar to previous findings on the gonadotropin-releasing actions of kisspeptins (Castellano et al., 2005; Tovar et al., 2006). Finally, as previously reported for kisspeptin (Castellano et al., 2005), repeated administration of NKB agonist was sufficient to at least partially rescue some of the indicators of puberty progression, such as VO and LH secretion, even against persistent conditions of energy deficit due to chronic subnutrition during the pubertal transition. Together, our studies suggest a role of metabolic cues in the modulation of NKB signaling at puberty, which is likely involved in transmitting information pertaining to body energy status to the Kiss $1 / \mathrm{GnRH}$ pathway governing puberty onset. Given our current data and the similarities with Kiss1/kisspeptin responses, it is highly plausible that such an effect is mediated, at least partially, via modulation of kisspeptin output in the ARC. However, we cannot rule out the contribution of additional, kisspeptin-independent pathways for the stimulatory effects of $\mathrm{NKB}$ on the gonadotropic axis at puberty.

Puberty is a key developmental event that is under the control of an intricate network of interacting peripheral signals and central transmitters that cooperate to ensure proper pubertal maturation. Our current data are the first to thoroughly document the roles of NKB signaling in this phenomenon, a physiological function that is seemingly linked (and possibly subordinated) to that of kisspeptins and sensitive to metabolic cues, which are likely to conduct (part of) their modulatory effects on puberty onset via regulation of the hypothalamic NKB system.

\section{References}

Amstalden M, Coolen LM, Hemmerle AM, Billings HJ, Connors JM, Goodman RL, Lehman MN (2010) Neurokinin 3 receptor immunoreactivity in the septal region, preoptic area and hypothalamus of the female sheep: colocalisation in neurokinin B cells of the arcuate nucleus but not in gonadotrophin-releasing hormone neurones. J Neuroendocrinol 22:1-12.

Bentsen AH, Ansel L, Simonneaux V, Tena-Sempere M, Juul A, Mikkelsen JD (2010) Maturation of kisspeptinergic neurons coincides with puberty onset in male rats. Peptides 31:275-283.

Billings HJ, Connors JM, Altman SN, Hileman SM, Holaskova I, Lehman MN, McManus CJ, Nestor CC, Jacobs BH, Goodman RL (2010) Neurokinin $B$ acts via the neurokinin-3 receptor in the retrochiasmatic area to stimulate luteinizing hormone secretion in sheep. Endocrinology 151:3836-3846.

Castellano JM, Navarro VM, Fernández-Fernández R, Nogueiras R, Tovar S, Roa J, Vazquez MJ, Vigo E, Casanueva FF, Aguilar E, Pinilla L, Dieguez C, Tena-Sempere M (2005) Changes in hypothalamic KiSS-1 system and restoration of pubertal activation of the reproductive axis by kisspeptin in undernutrition. Endocrinology 146:3917-3925.

Castellano JM, Navarro VM, Fernández-Fernández R, Castano JP, Malagon MM, Aguilar E, Dieguez C, Magni P, Pinilla L, Tena-Sempere M (2006) Ontogeny and mechanisms of action for the stimulatory effect of kisspep- tin on gonadotropin-releasing hormone system of the rat. Mol Cell Endocrinol 257-258:75-83.

Castellano JM, Bentsen AH, Mikkelsen JD, Tena-Sempere M (2010) Kisspeptins: bridging energy homeostasis and reproduction. Brain Res 1364:129-138.

Chowen JA, Argente J, Vician L, Clifton DK, Steiner RA (1990) Proopiomelanocortin messenger RNA in hypothalamic neurons is increased by testosterone through aromatization to estradiol. Neuroendocrinology 52:581-588.

Clarkson J, Boon WC, Simpson ER, Herbison AE (2009) Postnatal development of an estradiol-kisspeptin positive feedback mechanism implicated in puberty onset. Endocrinology 150:3214-3220.

Cunningham MJ, Scarlett JM, Steiner RA (2002) Cloning and distribution of galanin-like peptide mRNA in the hypothalamus and pituitary of the macaque. Endocrinology 143:755-763.

Fernandez-Fernandez R, Martini AC, Navarro VM, Castellano JM, Dieguez C, Aguilar E, Pinilla L, Tena-Sempere M (2006) Novel signals for the integration of energy balance and reproduction. Mol Cell Endocrinol 254-255:127-132.

García-Galiano D, van Ingen Schenau D, Leon S, Krajnc-Franken MA, Manfredi-Lozano M, Romero-Ruiz A, Navarro VM, Gaytan F, van Noort PI, Pinilla L, Blomenröhr M, Tena-Sempere M (2012) Kisspeptin signaling is indispensable for neurokinin $\mathrm{B}$, but not glutamate, stimulation of gonadotropin secretion in mice. Endocrinology 153:316-328.

Gianetti E, Tusset C, Noel SD, Au MG, Dwyer AA, Hughes VA, Abreu AP, Carroll J, Trarbach E, Silveira LF, Costa EM, de Mendonça BB, de Castro M, Lofrano A, Hall JE, Bolu E, Ozata M, Quinton R, Amory JK, Stewart SE, et al (2010) TAC3/TACR3 mutations reveal preferential activation of gonadotropin-releasing hormone release by neurokinin B in neonatal life followed by reversal in adulthood. J Clin Endocrinol Metab 95:2857-2867.

Gill JC, Wang O, Kakar S, Martinelli E, Carroll RS, Kaiser UB (2010) Reproductive hormone-dependent and -independent contributions to developmental changes in kisspeptin in GnRH-deficient hypogonadal mice. PLoS One 5:e11911.

Gottsch ML, Cunningham MJ, Smith JT, Popa SM, Acohido BV, Crowley WF, Seminara S, Clifton DK, Steiner RA (2004) A role for kisspeptins in the regulation of gonadotropin secretion in the mouse. Endocrinology 145:4073-4077.

Han SK, Gottsch ML, Lee KJ, Popa SM, Smith JT, Jakawich SK, Clifton DK, Steiner RA, Herbison AE (2005) Activation of gonadotropin-releasing hormone neurons by kisspeptin as a neuroendocrine switch for the onset of puberty. J Neurosci 25:11349-11356.

Hill JW, Elmquist JK, Elias CF (2008) Hypothalamic pathways linking energy balance and reproduction. Am J Physiol Endocrinol Metab 294:E827-832.

Lehman MN, Coolen LM, Goodman RL (2010) Minireview: kisspeptin/ neurokinin $\mathrm{B} /$ dynorphin (KNDy) cells of the arcuate nucleus: a central node in the control of gonadotropin-releasing hormone secretion. Endocrinology 151:3479-3489.

Navarro VM, Tena-Sempere M (2011) Neuroendocrine control by kisspeptins: role in metabolic regulation of fertility. Nat Rev Endocrinol 8:40-53.

Navarro VM, Castellano JM, Fernández-Fernández R, Barreiro ML, Roa J, Sanchez-Criado JE, Aguilar E, Dieguez C, Pinilla L, Tena-Sempere M (2004a) Developmental and hormonally regulated messenger ribonucleic acid expression of KiSS-1 and its putative receptor, GPR54, in rat hypothalamus and potent luteinizing hormone-releasing activity of KiSS-1 peptide. Endocrinology 145:4565-4574.

Navarro VM, Fernández-Fernández R, Castellano JM, Roa J, Mayen A, Barreiro ML, Gaytan F, Aguilar E, Pinilla L, Dieguez C, Tena-Sempere M (2004b) Advanced vaginal opening and precocious activation of the reproductive axis by KiSS-1 peptide, the endogenous ligand of GPR54. J Physiol 561:379-386.

Navarro VM, Gottsch ML, Chavkin C, Okamura H, Clifton DK, Steiner RA (2009) Regulation of gonadotropin-releasing hormone secretion by kisspeptin/dynorphin/neurokinin B neurons in the arcuate nucleus of the mouse. J Neurosci 29:11859-11866.

Navarro VM, Castellano JM, McConkey SM, Pineda R, Ruiz-Pino F, Pinilla L, Clifton DK, Tena-Sempere M, Steiner RA (2011a) Interactions between kisspeptin and neurokinin B in the control of GnRH secretion in the female rat. Am J Physiol Endocrinol Metab 300:E202-E210.

Navarro VM, Gottsch ML, Wu M, García-Galiano D, Hobbs SJ, Bosch MA, 
Pinilla L, Clifton DK, Dearth A, Ronnekleiv OK, Braun RE, Palmiter RD, Tena-Sempere M, Alreja M, Steiner RA (2011b) Regulation of NKB Pathways and Their Roles in the Control of Kiss1 Neurons in the Arcuate Nucleus of the Male Mouse. Endocrinology 152:4265-4275.

Oakley AE, Clifton DK, Steiner RA (2009) Kisspeptin signaling in the brain. Endocr Rev 30:713-743.

Ojeda SR, Skinner MK (2006) Puberty in the rat. In: The physiology of reproduction (Neill JD, ed), pp 2061-2126. San Diego: Academic/Elsevier.

Ojeda SR, Lomniczi A, Sandau U, Matagne V (2010) New concepts on the control of the onset of puberty. Endocr Dev 17:44-51.

Parent AS, Teilmann G, Juul A, Skakkebaek NE, Toppari J, Bourguignon JP (2003) The timing of normal puberty and the age limits of sexual precocity: variations around the world, secular trends, and changes after migration. Endocr Rev 24:668-693.

Paxinos G, Watson C (2009) The rat brain in stereotaxic coordinates, 6th edition. New York: Academic.

Pineda R, Garcia-Galiano D, Roseweir A, Romero M, Sanchez-Garrido MA, Ruiz-Pino F, Morgan K, Pinilla L, Millar RP, Tena-Sempere M (2010) Critical roles of kisspeptins in female puberty and preovulatory gonadotropin surges as revealed by a novel antagonist. Endocrinology 151:722-730.

Protter M, Morrey C (1964) College calculus with analytical geometry. Boston: Addison-Wesley.

Ramaswamy S, Seminara SB, Ali B, Ciofi P, Amin NA, Plant TM (2010) Neurokinin B stimulates GnRH release in the male monkey (Macaca mulatta) and is colocalized with kisspeptin in the arcuate nucleus. Endocrinology 151:4494-4503.

Ramaswamy S, Seminara SB, Plant TM (2011) Evidence from the agonadal juvenile male rhesus monkey (Macaca mulatta) for the view that the action of neurokinin B to trigger gonadotropin-releasing hormone release is upstream from the kisspeptin receptor. Neuroendocrinology 94:237-245.

Roa J, Aguilar E, Dieguez C, Pinilla L, Tena-Sempere M (2008) New fron- tiers in kisspeptin/GPR54 physiology as fundamental gatekeepers of reproductive function. Front Neuroendocrinol 29:48-69.

Roa J, Navarro VM, Tena-Sempere M (2011) Kisspeptins in reproductive biology: consensus knowledge and recent developments. Biol Reprod 85:650-660.

Sandoval-Guzmán T, Rance NE (2004) Central injection of senktide, an NK3 receptor agonist, or neuropeptide $\mathrm{Y}$ inhibits LH secretion and induces different patterns of Fos expression in the rat hypothalamus. Brain Res 1026:307-312.

Takase K, Uenoyama Y, Inoue N, Matsui H, Yamada S, Shimizu M, Homma T, Tomikawa J, Kanda S, Matsumoto H, Oka Y, Tsukamura H, Maeda KI (2009) Possible role of oestrogen in pubertal increase of Kiss 1/kisspeptin expression in discrete hypothalamic areas of female rats. J Neuroendocrinol 21:527-537.

Topaloglu AK, Reimann F, Guclu M, Yalin AS, Kotan LD, Porter KM, Serin A, Mungan NO, Cook JR, Ozbek MN, Imamoglu S, Akalin NS, Yuksel B, O'Rahilly S, Semple RK (2009) TAC3 and TACR3 mutations in familial hypogonadotropic hypogonadism reveal a key role for neurokinin B in the central control of reproduction. Nat Genet 41:354-358.

Tovar S, Vázquez MJ, Navarro VM, Fernández-Fernández R, Castellano JM, Vigo E, Roa J, Casanueva FF, Aguilar E, Pinilla L, Dieguez C, TenaSempere M (2006) Effects of single or repeated intravenous administration of kisspeptin upon dynamic $\mathrm{LH}$ secretion in conscious male rats. Endocrinology 147:2696-2704

True C, Kirigiti MA, Kievit P, Grove KL, Smith MS (2011) Leptin is not the critical signal for kisspeptin or luteinising hormone restoration during exit from negative energy balance. J Neuroendocrinol 23:1099-1112.

Wakabayashi Y, Nakada T, Murata K, Ohkura S, Mogi K, Navarro VM, Clifton DK, Mori Y, Tsukamura H, Maeda K, Steiner RA, Okamura H (2010) Neurokinin B and dynorphin A in kisspeptin neurons of the arcuate nucleus participate in generation of periodic oscillation of neural activity driving pulsatile gonadotropin-releasing hormone secretion in the goat. J Neurosci 30:3124-3132. 